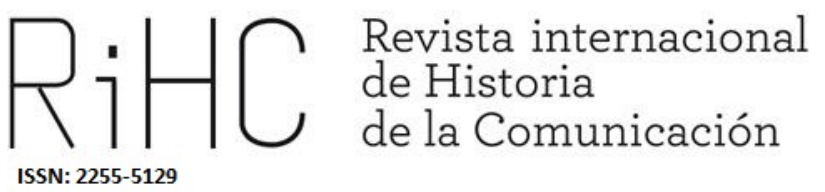

\title{
LITERATURA PUBLICADA EN EL PERIÓDICO EL CORREO ESPAÑOL
}

Literature published in the newspaper El Correo Español

DOI: http://dx.doi.org/10.12795/RiHC.2019.i12.16

Recibido: $13 / 03 / 2019$ Aceptado: 01/04/2019

Publicado: $15 / 06 / 2019$

Lydia Elizalde

Universidad Autónoma del Estado de Morelos, México

lydiaelizalde@uaem.mx

ORCID (ID) 0000-0003-4365-0102 
Resumen: En este artículo se describe el repertorio de la literatura publicada en México en el periódico EI Correo Español, durante la última década del siglo XIX, de noviembre de 1889 a mayo de 1898. Desde su prospecto, el diario españolista planteó la relevancia de la divulgación de literatura producida por autores españoles, así como el reconocimiento de las letras publicadas por mexicanos y autores de otros países de América Latina; incluyó traducciones de obras que lindaron entre el romanticismo y el modernismo, de autores europeos y de Norteamérica. La revisión de los contenidos literarios en el periódico españolista, multicitado en los estudios de la prensa decimonónica mexicana, es uno de los primeros acercamientos a la difusión de las letras en este diario; de esta manera se puede ver la diversidad de escritores, algunos reconocidos y otros nóveles que publicaron sus colaboraciones literarias.

Palabras clave: diario españolista, fin del siglo XIX, literatura, poesía y prosa, autores

\begin{abstract}
This article describes the production of literature which circulated in Mexico during the last decade of the 19th century, published in the newspaper El Correo Español from November 1889 to May 1898. From its prospect, the Spaniard journal raised the relevance of the dissemination of literature produced by Spanish authors, as well as the recognition of the writings published by Mexicans and authors from other Latin American countries. It also published translations of works that bounced between Romanticism and Modernism by European and American authors. The revision of the literary contents in this Spanish newspaper has been mentioned frequently in the studies of the nineteenth-century press in Mexico, and this is one of the first approaches to the diffusion of writings published on its pages. In this way it can be seen the diversity of writers, some recognized and other beginners, who published their literary works.
\end{abstract}

Keywords: Spaniard journal, end of the 19th century, literature, poetry and prose, writers

\title{
Introducción
}

Este artículo presenta un acercamiento a la literatura que circuló en el diario El Correo Español publicado en México de 1889 a 1914. La revisión de las colaboraciones literarias se centra en los primeros 10 años de su publicación, cuando su fundador -el escritor, editor y abogado-, Fernando Luis Juliet de Elizalde estuvo a cargo del periódico, del 9 de noviembre de 1889 y al 31 de mayo de 1898. El periódico tenía como función principal difundir información política, social y cultural de España, dirigida a españoles residentes en Mexico.

El primer estudio formalizado sobre el periódico españolista ${ }^{1}$ se publicó en 2016 en el libro: El Correo Español, aportes a la prensa periódica en México (1889-1898). Antes de

\footnotetext{
${ }^{1}$ El término españolista ha adquirido diversos sentidos según las circunstancias en que ha sido empleado y su significado es "afición por la cultura española". Su uso fue frecuente en el contexto del México 
la publicación de este libro, únicamente se habían realizado breves estudios sobre algunas temáticas publicadas en el periódico y sobre su editor. Del estudio detallado sobre el periódico, se derivó el libro Índices literarios. El Correo Español (1889-1898) publicado en 2017. En este se hace una revisión minuciosa de los contenidos literarios que difundió el periódico publicados en este periodo. Esto ha permitido reconocer la literatura finisecular que circulaba en la última década del siglo XIX y que preferentemente el periódico publicó en sus páginas. ${ }^{2}$ De manera propositiva, para la conformación de este artículo se entrelaza la información de ambas obras y se añaden reflexiones de especialistas sobre la difusión de la literatura en la prensa. ${ }^{3}$

\section{Sección literaria}

El trato privilegiado que tuvo la literatura en El Correo Español se revela a través del espacio dedicado primeramente a las letras españolas, le sigue la difusión de la literatura mexicana, e incluye la de otros países hispanoamericanos; asimismo, frecuentemente fueron difundidas traducciones de la literatura francesa, anglosajona, alemana y de otros países europeos. La divulgación de diversos géneros literarios: poesía, relatos cortos, cuento, novelas de folletín y reseñas literarias, manifiestan la conocida "invención de la difusión literaria," evidente en el periodismo que se difundió en México y en otras latitudes durante las últimas tres décadas del siglo diecinueve. ${ }^{4}$

Las colaboraciones que hicieron poetas y escritores, reconocidos y amateurs, en este periódico español y de manera destacada en periódicos nacionales que circulaban en ese final de siglo, fomentó el gusto por la lectura de obras de la literatura

independiente, después del primer tercio del siglo XIX. Sigue utilizándose en medios académicos para conceptuar algunos de los estudios socioculturales de españoles. También se conoce que la noción españolista tiene diferentes connotaciones en la Península Ibérica.

${ }^{2}$ El periódico El Correo Español tenía como función principal difundir información política, social y cultural de España y sus relaciones políticas y comerciales con México; estaba dirigida a los españoles residentes en este país.

${ }^{3}$ La constitución y permanencia del periódico, durante los diez primeros años de su edición marcaron su perspectiva editorial. La aceptación de los contenidos del periódico puede medirse por su demanda y continuidad.

${ }^{4}$ Sobre la divulgación de la literatura en la prensa en el siglo XIX en México, el escritor y periodista Rafael Perez Gay enfatiza: "La aventura más arriesgada y cierta, una de las obras más perfectas de la literatura mexicana fue el periodismo del siglo XIX [...] En ese litoral exuberante creció una insólita población de prosa y poesía que quiso que los libros del siglo diecinueve fueran los periódicos [...]" (1987). 
hispanoamericana y de la universal; además permitió reconocer otros géneros literarios, entre ellos la novela seriada y la crónica. ${ }^{5}$

En su primer número, El Correo Español presentó el prospecto que se mantendría en un consistente programa de trabajo. ${ }^{6}$ En la primera sección, la "española", y en la tercera, la "mexicana", se dedicaron espacios a difundir la producción literaria (El Correo Español 1889: 9-12). En estas, se publicaron, habitualmente, de cuatro a diez entregas en cinco números a la semana. La difusión de la literatura en este medio impreso buscó fomentar el gusto por la lectura de la literatura escrita en español.

La publicación de colaboraciones de poesía y prosa en El Correo Español es muestra de la difusión de los movimientos literarios de finales del siglo XIX que experimentaron con el lenguaje y cuyo exponente más destacado fue el modernismo, o que mantuvieron formas canónicas cercanas a este movimiento. En sus páginas se encuentran colaboraciones de autores cuyas obras lindan entre el romanticismo, el parnasianismo, el costumbrismo, el simbolismo y el modernismo, además de la alusión a autores de otros países que prefirieron la prosa realista y la naturalista. Por este motivo se da cuenta de cómo las diferentes manifestaciones literarias contribuyeron a la conformación de un espacio de difusión de la literatura en aquel periodo (Cuesta 2016: $6)$.

Es conveniente señalar que muchos de los autores contenidos en estas páginas poseían un estilo indefinido y seguían aún algunas de las pautas románticas, ${ }^{7}$ otros, sin embargo, buscaban abrirse paso para explorar nuevas formas del lenguaje literario. Actualmente se hacen relecturas de aspectos ya explorados por la crítica, ${ }^{8}$ que permiten analizar la tradición prosística extendida desde mediados del siglo XIX al oponerse a los modos tradicionales del uso del lenguaje y caracterizar la prosa con "la misma virginidad expresiva de la poesía, de la misma novedad combinatoria que exige para el verso" (Gutiérrez 1992: 106).

Algunos autores no siguieron esta propuesta y expusieron su inconformidad en otros periódicos del país. Sin embargo, en El Correo Español y, principalmente, su fundador Luis J. de Elizalde fue partidario de abrir las puertas a la diversidad de tendencias

\footnotetext{
${ }^{5}$ La circulación de estos contenidos literarios en ocasiones provenían de diarios españoles, publicados en la península, y muchas de las colaboraciones también se duplicaban en los principales diarios mexicanos del periodo.

6 El seguimiento de este programa fue evidente en los primeros diez años de su publicación, con las diferentes tendencias que daba el editor en jefe.

${ }^{7}$ Max Henríquez Ureña señala que "el romanticismo, aunque en decadencia, imperaba todavía, pero conviene advertir que aun los poetas de pura cepa romántica, por lo menos aquellos que podemos considerar como poetas mayores, ponían celoso cuidado en la expresión y no se circunscribían a determinados metros y combinaciones" (Henríquez 1962: 43).

${ }^{8}$ Revisión de José Ismael Gutiérrez (2007) en Perspectivas sobre el modernismo hispanoamericano.
} 
literarias. Por ello, el periódico permite hacer acercamientos estimables para la producción literaria española, mexicana y latinoamericana del periodo (Elizalde 2017: 19), publicada en sus páginas.

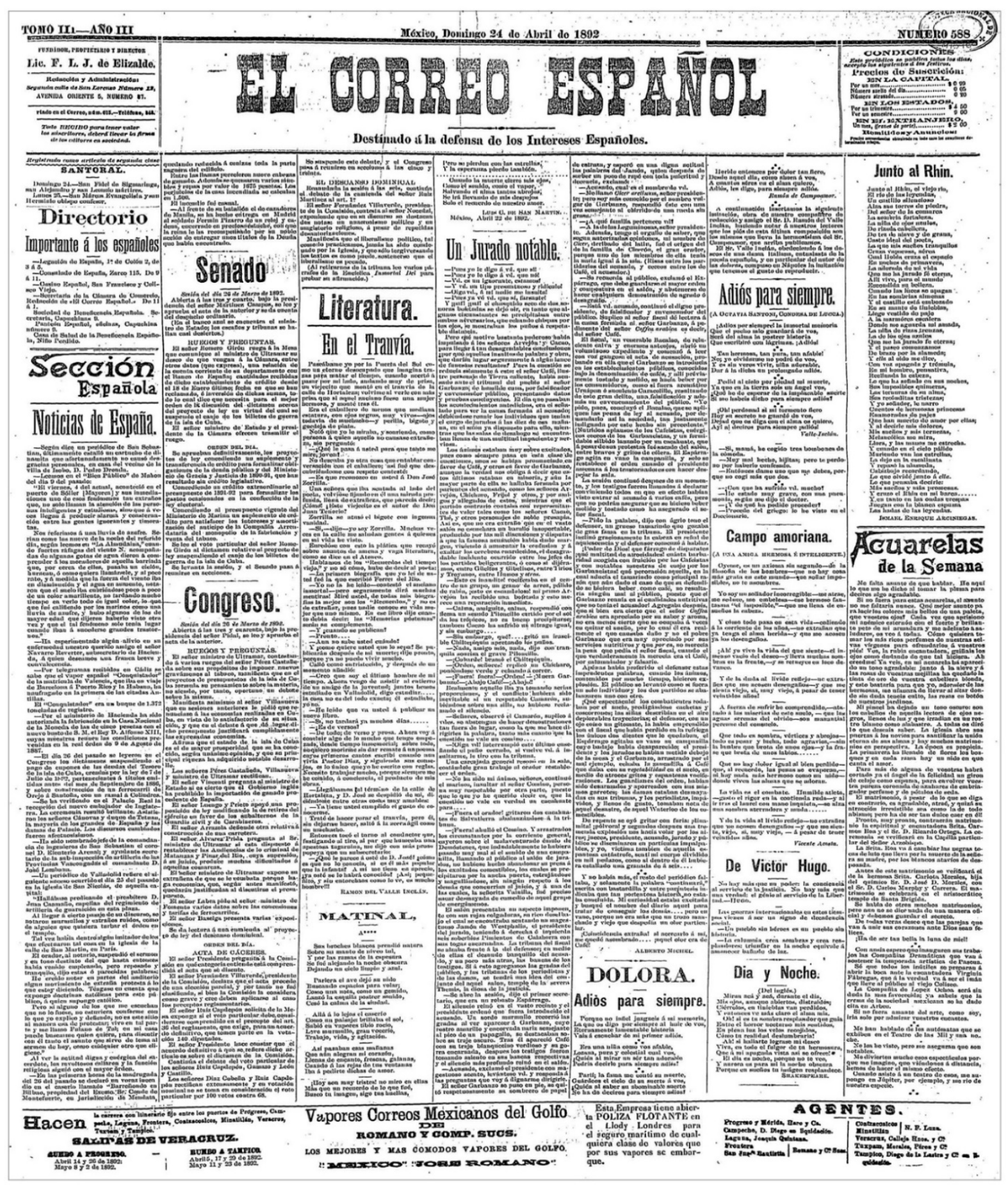

Figura 1. Muestra de inserciones literarias en El Correo Español. ${ }^{9}$

\footnotetext{
${ }^{9}$ Este ejemplar muestra el énfasis que dio el periódico a las colaboraciones literarias (Tomo III, año III, número 588, domingo 24 de abril de 1892). No se pretende su lectura, sino mostrar la diagramación de la primera página, en donde sobresale del cabezal del periódico y el espacio dedicado a la literatura -
} 
Inicialmente, el periódico se publicó en formato de gaceta y presentó la poesía y la prosa en varias páginas a la mitad de la edición. ${ }^{10} \mathrm{~A}$ partir de junio de 1890 hasta mayo de 1891, cuando el periódico se formalizó con el cambio de formato a cuatro páginas en tamaño sábana, la sección literaria se incluyó en la primera y segunda páginas. Posteriormente, desde octubre de 1892 siguieron ubicándose los textos en las dos primeras páginas del periódico sin delimitar las entregas a una sección. A partir de las ediciones de 1895 , las inserciones literarias se redujeron de cinco hasta dos por número.

\section{Editores}

La relación epistolar del intelectual y empresario santanderino, asentado en México, Telésforo García, con su compatriota Emilio Castelar, presidente de la primera República Española (1873-1874) y también escritor, facilitó que se publicaran en El Correo Español las colaboraciones de nóveles escritores españoles, quienes portaban cartas de recomendación para que sus obras se publicasen en el diario españolista (Mora 2009: 16). La historiadora Lilia Vieyra reseña que la actividad periodística de los ibéricos en México permitió el desarrollo de un movimiento cultural paralelo al que se vivía en España (2007). ${ }^{11}$ Habitualmente la publicación de obras de autores reconocidos se hacía a través de redes o agencias de divulgación, que vendían las colaboraciones a los periódicos, resultando esta una tarea rentable para los escritores (Elizalde 2017: 13).

En el artículo titulado "La prensa del siglo XIX como medio de difusión de la literatura hispanoamericana", Almuneda Mejías y Alicia Arias mencionan que muchos de los estudiosos del periodo sobre literatura, de historia o sociología, consideran la centuria del XIX el siglo de la prensa escrita (1998: 241). Refieren esto con la celebrada declaración de Emilio Castelar: "Cuando tomo en mis manos un periódico, cuando recorro sus columnas, cuando considero la diversidad de sus materias y la riqueza de sus

prosa y poesía- en cinco de las siete columnas. Publicación en acceso abierto, Hemeroteca Digital de México, Biblioteca Nacional de México, UNAM.

10 En el formato gaceta, el número de páginas del periódico varió de 32,44 y hasta 48 . El alcance del periódico puede verse a partir del primer año de su publicación, cuando el tiraje del periódico fue de 4000 ejemplares en correspondencia con el número de suscriptores. La distribución del periódico se hacía en la República Mexicana, en los Estados Unidos de Norteamérica y en España

11 “La emigración del norte de España a México fue un aspecto que se desarrolló en las postrimerías del siglo XVIII, la mayoría era originaria de la región cantábrica: Asturias, Navarra y las montañas de Burgos. Antonia Pi-Suñer también asienta que la zona norte de España destacó como una región caracterizada por su emigración a América" (Vieyra 2012: 5). 
noticias, no puedo menos de sentir un rapto de orgullo por mi siglo" (Castelar en Mejías y Arias 1998: 241). ${ }^{12}$

Luis J. de Elizalde (1854-1909) ${ }^{13}$ fue favorecido por la red de editores, escritores y periodistas españoles, a quienes Telésforo García había empezado a reunir quince años antes $^{14}$ (Vieyra, 2007). En 1888 se hizo cargo de la dirección editorial del periódico El Pabellón Español; y en 1889 inició la publicación de El Correo Español. En este periódico de su propiedad, despunta la conformación de un equipo editorial asentado, en donde de manera adicional a las tareas administrativas, algunos de los jefes de redacción también participaban con entregas literarias, reseñas y crónicas periodísticas, y en ocasiones fueron propietarios asociados del diario. Entre ellos sobresalen: Lorenzo A. Miranda, Juan Miguel Sancho, Francisco Romero, Luis del Toro, Alberto Araus, Francisco Durante. Las funciones de los editores se presentaron en el cabezal del diario o en el recuadro legal, en la primera o en la segunda páginas, cuidando siempre la autenticidad y responsabilidad de la fuente para la difusión de la información.

De ellos se presenta a continuación una breve descripción de las actividades que realizaron como editores y escritores. Los editores asociados, dedicados principalmente a las tareas de edición fueron: Lorenzo A. Miranda, además de editor hizo colaboraciones de poesía al periódico; el editor Juan M. Sancho, fue accionista del Banco Mercantil de Veracruz (Rajo Serventich 2017); Francisco Romero fue jefe de redacción y accionista del periódico durante la segunda época durante tres meses y José Sánchez Somoano accionista durante dos meses.

A estos editores se suman los que tuvieron una presencia más amplia en el periódico desarrollando actividades editoriales y literarias. Destaca el periodista veracruzano de origen español, Luis del Toro (1872-1920). Inicialmente había colaborado con entregas de poesía para El Correo Español (1890-1894); ${ }^{15}$ posteriormente fue jefe de redacción del periódico (1892) y tras este cargo fue editor propietario y director del 10 de septiembre de 1893 al 29 de julio de 1894. Colaborador en otros diarios publicados en el país, entre ellos en La Bandera Veracruzana, El Diario del Hogar y El Partido Liberal.

\footnotetext{
${ }^{12}$ Las investigadoras retoman esta cita de Oliver Bertrand, Oratoria, política y oradores del ochocientos, (1960), p. 31, así como de María Cruz Seoane, Historia del periodismo en España. II. El siglo XIX, (1968), p. 11.

13 A mediados de la década de 1880, J. de Elizalde emigró a México y se incluye, por el periodo de su internación al país, en el grupo inmigrantes que llegó con una profesión y medios para establecer una empresa, en su caso, una sociedad editorial.

${ }^{14}$ Telésforo García realizó su obra periodística en México, inicialmente colaborando en El Precursor (1874 - 1876); en 1876 continuó con colaboraciones en el diario La lberia (1a época), fundado por su compatriota Anselmo de la Portilla. García fundó El Centinela Español (1881), órgano informativo para la Colonia Española y de utilidad para los hombres de negocios pues publicaba noticias sobre cosechas, producciones y comercialización (García 2003: 17, en Ledezma: 2013).

15 En este periodo colaboró con cinco entregas de poesía.
} 
Propietario de El Correo de México y redactor en el periódico La Nación (1894) de J. de Elizalde; cofundador de El Globo (1895) de Carlos Rougmanac. Escribió en el semanario La Raza Latina y en El Monitor Republicano; fue director y gerente de El Universal (del 3 octubre 1900 al 7 diciembre 1901) (Díaz Alejo 2002: 92). Colaboró en el bisemanario del Partido Científico, El Debate (1909); fundó el periódico huertista El Independiente $(1913-1914)^{16}$ (Ross 1965: 369).

Francisco Durante fue redactor en el periódico El Pensamiento Español, en 1885 en la Habana, y en Madrid de 1891 en El Resumen. Utilizó el pseudónimo Duterán y colaboró alternadamente con Araus en la redacción de "Croniquillas" para El Correo Español. En 1897 Duterán compiló sus textos satíricos en el libro titulado Salsa Mambisa, editado con una portada litográfica del caricaturista español Ángel Pons. ${ }^{17}$ En 1900 regresó a Madrid, y colaboró en la revista Blanco y Negro y en otras publicaciones literarias; en 1903 fue redactor, en Madrid, para el Diario Universal (Ossorio y Bernard 1903: 112).

La presencia de los diferentes jefes de redacción y editores se manifiesta en la selección de los contenidos literarios; estos dejan ver las redes de divulgación de literatura en ese final de siglo, así como las afinidades literarias compartidas entre ellos, incluyendo los lazos de amistad.

Entre los escritores y periodistas mexicanos, se citan a continuación tres de ellos estuvieron comprometidos con la empresa editorial de El Correo Español:

Félix María Alcérreca (1845-1894), escritor y político originario de Puebla, fue miembro de la Sociedad Mexicana de Geografía y Estadística y Tesorero de la Prensa Asociada de México. Fundó diversas sociedades artísticas y literarias; fue diputado del Congreso de la Unión; ocupó el puesto de Presidente del Colegio Nacional de Escribanos. Su cercanía y camaradería con Luis J. de Elizalde es patente en las páginas del diario al colaborar mediante entregas seriadas con las novelas de folletín "Culpa y castigo" (en diez entregas de diciembre de 1889 a febrero de 1890) y "Luchas del destino" (con el mismo número de colaboraciones de marzo a junio de 1890). ${ }^{18}$

A la edición de El Correo Español se sumó el poeta y periodista mexicano Manuel Larrañaga y Portugal (1868-1919), originario de Guanajuato. Desde 1890 inició la

\footnotetext{
${ }^{16}$ Este diario fue el órgano oficial del fallido gobierno de Victoriano Huerta. Con su cierre, en 1914 partió a España.

${ }^{17}$ Ángel Gutiérrez Pons, notable dibujante y caricaturista, firmaba sus trabajos con A. Pons. En Madrid colaboró en diversas publicaciones periódicas, entre ellas Madrid Cómico, La Broma, El Liberal, Los Madriles, Pluma y Lápiz, La Caricatura (1892), La Lidia y La Correspondencia (Ossorio y Bernard, 1903, p. 192). En 1895 emigró a México, donde trabajó en periódico El Alacrán y fue responsable de la edición de El Correo Español, del 21 de julio al 2 de septiembre de 1899.

${ }^{18}$ Alcérreca, también escribió en El Polífono, periódico dominical de música, literatura, ciencias, artes, noticias y avisos; y fue un activo músico, chelista cofundador de la Orquesta del Conservatorio Nacional (1883), director de un grupo coral de música sacra y compositor (Vargas Cruz, 2014).
} 
entrega de 40 colaboraciones en la columna "Con mi musa", de mayo 1890 a agosto de 1892 , incluyendo doce textos de obras de poetas mexicanos. Tuvo el cargo de jefe de redacción en el periódico hasta su retiro temporal en noviembre de 1892. A su regreso publicó la sección "Álbum poético español" que presentó a reconocidos escritores ibéricos en 38 entregas, de noviembre de 1894 a febrero de 1895. También publicó algunos poemas en las destacadas revistas literarias mexicanas: la Revista Azul, publicada semanalmente en la Ciudad de México de 1894 a 1896 y la Revista Moderna, principal difusora del modernismo, que se publicó de 1898 a 1903, en esta ciudad y en algunos estados del país. Fue redactor en El Mundo Ilustrado y redactor en jefe de la Revista de la Instrucción Pública Mexicana, además de editor de la revista Frivolidades. Semanario Ilustrado; fue jefe de redacción del semanario independiente de caricaturas El Hijo del Ahuizote Nacional (1912-1913) y en El Nacionalista (1917); en la edición de la tarde de El Diario; es autor del poemario Flores de iris (Ceballos en Viveros 2006: 93).

Otro valioso periodista y escritor mexicano fue Agustín Alfredo Núñez, quien publicó en el periódico ensayos y obras poéticas a partir de octubre 1890 a $1892 .{ }^{19}$ En 1894, Núñez colaboró como jefe de redacción en La Nación, periódico de J. de Elizalde, ${ }^{20}$ y mantuvo sus colaboraciones para El Correo Español hasta diciembre de 1896. Publicó en varios periódicos reseñas culturales, entre estas "Crónicas de la semana" que firmó con el pseudónimo Alertes. Publicó el libro Bagatelas (1894), además de artículos de costumbres en varios periódicos (Ceballos en Viveros 2006: 93).

De esta manera se enfatiza que las colaboraciones de estos y las de otros escritores y periodistas mexicanos en El Correo Español, eran difundidas en los círculos literarios de fin de siglo. Algunas de ellas se publicaron también en otros diarios nacionales que tenían una amplia popularidad, entre estos: El Siglo Diez y Nueve, La Patria, El Partido Liberal, El Monitor Republicano y El Universal.

Las colaboraciones en El Correo Español marcaron el énfasis literario del diario durante la primera época de su publicación, de noviembre de 1889 a marzo de 1891. Dos años después, el fundador del diario contó con la colaboración del periodista Ángel Prieto Álvarez (de abril de 1891 a febrero de 1892) quien aportó obras de autores españoles de diversos géneros, entre ellos escritores de teatro.

Después de esta experiencia, J. de Elizalde alternó el cargo de director, y estableció una participación, como asociados, con los editores Juan Miguel Sancho y Luis del Toro (de septiembre de 1893 a julio de 1894) quienes continuaron la línea editorial del periódico y la publicación de escritos de autores españoles y latinoamericanos. Desde finales de

\footnotetext{
${ }^{19}$ En una carta dirigida a El Correo Español, del 2 de noviembre de 1892, el escritor Agustín Alfredo Núñez y el poeta Manuel Larrañaga y Portugal, se despidieron del diario después de tres años de colaboraciones continuas. Ambos regresaron a colaborar con el diario a partir de 1894.

20 Este periódico se publicó de mayo a noviembre de 1894 y duplicó muchos de los artículos de El Correo Español; pretendía llegar a más lectores, pero su edición no prosperó.
} 
1894, cuando J. de Elizalde retomó la dirección del diario, hasta mediados de 1898, el número de entregas literarias fue irregular y paulatinamente se fueron sustituyendo por ensayos y notas informativas sobre la situación geopolítica española.

\section{Literatos}

En los primeros diez años de su edición, El Correo Español publicó textos de escritores valorados por sus aportes al lenguaje y a la literatura española. Y con el fin de tener un ejemplo de la relevancia de la literatura publicada y su incidencia en las formas culturales, se presentan los nombres de los autores consolidados y el número de sus colaboraciones: españoles, mexicanos y latinoamericanos; se destacan también las entregas de escritoras de varias nacionalidades:

- Escritores españoles. Manuel del Palacio (poesía, 65 colaboraciones); Luis Taboada (prosa, 60 colaboraciones); Ramón de Campoamor (poesía, 40 colaboraciones); Salvador Rueda (poesía, 40 colaboraciones); Sinesio Delgado (poesía, 27 colaboraciones); José Zorrilla (poesía y teatro, 18 colaboraciones); Ramón del Valle-Inclán ${ }^{21}$ (poesía y prosa, siete colaboraciones); Eduardo Bustillo (poesía, seis colaboraciones).

- Escritores mexicanos. José Juan Tablada (poesía, 65 colaboraciones); Salvador Díaz Mirón (prosa, 60 colaboraciones); Luis G. Urbina (poesía, 40 colaboraciones); Juan de Dios Peza (poesía, 40 colaboraciones); Manuel Gutiérrez Nájera ${ }^{22}$ (poesía, nueve colaboraciones).

Cabe mencionar que en las páginas del diario se hicieron homenajes a notables escritores por su muerte: en febrero de 1893, se publicaron varios ensayos y algunas de las obras de José Zorrilla; y de Manuel Gutiérrez Nájera, del 21 al 28 de marzo de 1895, el diario presentó una serie de ensayos sobre la concepción literaria del autor, firmados por el escritor y crítico asturiano Félix Gavito.

\footnotetext{
${ }^{21}$ El joven escritor Valle-Inclán (1866-1936) publicó sus revelaciones literarias durante su primera estadía en México en El Correo Español, en siete entregas. Estas se publicaron del 17 de abril al 8 de mayo de 1892; algunas ya ellas las había publicado en El Globo y El Imparcial en Madrid, antes de venir a México; solo la última colaboración, "A una mujer ausente por su muerte" fue inédita. Estas se publicaron en la primera página del diario, a partir de la segunda entrega.

${ }^{22}$ Gutiérrez Nájera fue el precursor del modernismo en México. Fundó junto con Carlos Díaz Dufoo, la Revista Azul, un semanario que aparecía junto a la edición dominical del diario El Liberal, publicación que circuló de 1894 a 1896.
} 
- Escritores de varios países de Latinoamérica. Rubén Darío ${ }^{23}$ (nicaragüense, poesía y prosa 30 colaboraciones); Vicente Acosta (salvadoreño, poesía 18 colaboraciones); Miguel Antonio Caro (colombiano, poesía y traducción 12 colaboraciones); Olegario V. Andrade (argentino, prosa nueve colaboraciones); José Antonio Calcaño (venezolano, poesía ocho colaboraciones); Rafael Obligado (argentino, poesía seis colaboraciones); Antonio Sellén (cubano, poesía cuatro colaboraciones); Jorge Isaacs (colombiano, poesía tres colaboraciones); Guillermo Matta (chileno, poesía tres colaboraciones); Ricardo Palma (peruano, poesía tres colaboraciones); Carlos Amézaga (peruano, poesía y prosa tres colaboraciones); Máximo Soto Hall (guatemalteco, poesía dos colaboraciones); Víctor Arreguine (uruguayo, poesía una colaboración).

Sobresalen, asimismo, en este periódico finisecular, las colaboraciones realizadas por mujeres dedicadas a la literatura, con obras de poesía y prosa referenciadas en las antologías literarias de sus países; algunas de ellas también colaboraron con traducciones del latín, italiano y francés. ${ }^{24}$

- Escritoras españolas. Emilia Pardo Bazán (prosa, 26 colaboraciones); Josefa Pujol de Collado $^{25}$ (prosa, cuatro colaboraciones); Julia de Asensi (poesía tres colaboraciones); y con una colaboración: Juana Marín Baldo de Martínez (poesía); Patrocinio de Biedma (prosa); Concepción Gimeno (prosa); Blanca de los Ríos (prosa); Emilia Serrano Wilson (prosa).

- Escritoras latinoamericanas. Laura Méndez de Cuenca ${ }^{26}$ (mexicana, poesía y traducción, tres colaboraciones); María de los Ángeles Otero ${ }^{27}$ (mexicana, poesía, una colaboración); Nieves Xenes (cubana, poesía dos colaboraciones); Mercedes Matamoros (cubana, poesía dos colaboraciones); Beatriz Franco Prosa (cubana, prosa, una colaboración).

\footnotetext{
${ }^{23}$ Contar con las colaboraciones del máximo representante del modernismo literario en lengua española, muestra la contemporaneidad de las letras publicadas en El Correo Español.

24 Las pocas colaboraciones de escritoras se citan aparte con el fin de resaltar su presencia en el periódico, sin caer en un reduccionismo de la literatura producida por mujeres.

${ }^{25}$ Josefa Pujol, junto con su esposo Casimiro del Collado, formó parte de los colaboradores iniciales en El Correo Español. Ella participó en revisiones editoriales e hizo traducciones de obras clásicas. Cuando muere su conyugue, Pujol regresa a España y desarrolla su obra literaria.

${ }^{26}$ Laura Méndez de Cuenca (1853-1928), pedagoga mexiquense quien además de hacer una exploración de la modernidad, escribió crónicas descriptivas sobre aspectos educativos, entre esto cuestiones de higiene y salud, acerca de la condición de la mujer, además de crónicas de ensayo-literarias (Milada Bazant, 2009).

${ }^{27}$ En el libro La lira poblana publicada se presentan poesías de María de los Ángeles Otero, entre las de otras jóvenes letristas: Rosa Carreto, Severa Aróstegui, Leonor Craviotto, María Trinidad Ponce y Carreón, Luz Trillanes y Arrillaga. Este compendio fue publicado para presentarse en la Exposición Internacional de Chicago, editado en la imprenta de Francisco Díaz de León Sucesores, en 1893, por encargo del Gobierno del Estado de Puebla. La exposición tuvo un interés especial al estudiar la presencia de la mujer en la educación y las letras en el siglo XIX (Guzmán, 2014).
} 
- Escritoras de otras nacionalidades. Carmen Sylva ${ }^{28}$ (prusiana, poesía, una colaboración); Matilde Serao $^{29}$ (italiana, prosa, una colaboración).

Los temas tratados en obras de poesía y prosa por autoras más prolíficas, dejan ver su erudición: unas buscaron nuevos lenguajes expresivos o incursionaron en nuevos géneros literarios narrando experiencias íntimas, otras empezaron a tener presencia en la crónica periodística. En ocasiones publicaban con el apellido del esposo después del suyo o utilizaban pseudónimos o solo la inicial para su nombre; esta identidad adoptada fue un reflejo de los esquemas tradicionales en los que se definía la literatura femenina del periodo como un conjunto, sin diferenciar sus particularidades literarias (Simón Palmer 1989: 594). Pocos fueron los escritos de mujeres que tuvieron la atención de la crítica literaria; la mayoría de estos se publicaban habitualmente en revistas "femeninas", otros en libros relacionadas con la docencia y la ética religiosa; pero algunos empezaron a ser visibles en diferentes diarios y semanarios a partir de las últimas décadas del siglo XIX.

Una buena cantidad de obras literarias creadas originalmente en otros idiomas francés, inglés, italiano, alemán- se traducían al español para su divulgación; algunas se difundían, de manera parcial en la prensa de finales siglo y en las inaugurales revistas culturales.

En El Correo Español, se incluyeron traducciones de obras poéticas y en prosa de reconocidos escritores franceses, muchas de ellas circulaban en periódicos y revistas culturales europeas e hispánicas del siglo XIX, entre las más difundidas destacan las obras de Alphonse Daudet, Theophile Gautier, Catulle Mendès, Francois Coppèe, Emile Zola, Alfred de Musset, y los poemas de Victor Hugo; se añaden cuentos de Guy de Maupassant. También se presentan traducciones de autores alemanes, H. Heine y J. W. Goethe; los rusos, Ivan Turguenev y Lev Tolstoi; y los norteamericanos Edgar A. Poe y W. H. Longfellow; hubo pocas entregas de autores italianos, algunas de la literatura clásica y otras escritas por cartógrafos del XIX (Elizalde, 2017, p. 20).

Es conocido que algunas traducciones del francés, principalmente, fueron realizadas por el director del periódico; en otras ocasiones por autores y colaboradores del periódico o por escritores conocidos por sus trabajos de traducción, entre estos: Sully Prudhomme, los españoles Ángel Lasso de la Vega, Ismael Enrique Arciniegas y Ángel Pons; el poeta peruano Ricardo Palma; el puertorriqueño F. J. Amy; los mexicanos Enrique González Llorca, Laura Méndez de Cuenca, Felipe Paniagua, Toribio Soto e incluso se publicaron traducciones realizadas por el escritor José Juan Tablada.

\footnotetext{
${ }^{28}$ Carmen Sylva, pseudónimo de la escritora prusiana Elizabeth von Weid, reina consorte de Rumania (1869-1914).

${ }^{29}$ Sarao, novelista y periodista italiana de origen griego. Fundó y editó varios diarios en Italia, particularmente /l Mattino.
} 
Cada traductor imprimía un estilo propio y algunas de estas resultaron versiones libres de composición poética. En ocasiones se convirtieron en paráfrasis de algún tema recurrente, las cuales revelaban la influencia del traductor, mediante la inserción de su nombre en el título o en la dedicatoria (Elizalde, 2017, p. 21).

Sobre las firmas de los autores, en varias de las colaboraciones signaron con pseudónimos, de las cuales, en ocasiones, ha sido difícil seguir la huella para determinar el nombre del autor, entre ellos: Chomín El Memo (acaso del vasco Txomin), Marrasquino (quien firmaba la sección “Maremagnum”), Farfalla, Martinto, Viador; solo de algunos biografías se pudo encontrar el nombre del autor de la colaboración literaria (Elizalde 2017: 18). En los apuntes biográficos de muchos de estos escritores se conocen los ppseudónimos que utilizaban.

Entre los distintivos utilizados destacan también los nombres referentes a la cultura occidental: Laertes, Lohengrin, Parsifal, entre otros (2017: 18). También era frecuente la presentación de siglas reconocidas en la mesa de redacción del periódico, quienes habían presentado colaboraciones anteriores con más de cien menciones: A.F., C.D., L.O., M.C., N.F.G., P.R., X., X.Y.X., y la firma $X^{* * *}$.

Se muestran en este periódico obras de autores españoles provenientes de diferentes regiones. Estas entregas tienen una relación con el enfoque y las relaciones del editor en turno; sobresalen así en ciertos periodos los autores del País Vasco, Asturias, Santander y Aragón, los de Cataluña y Galicia, en otros los de Valencia y Andalucía y de la meseta central de Castilla y León; se suman los autores mexicanos asentados principalmente en la Ciudad de México, en Puebla, Veracruz, otros en Guadalajara y los de región de tierra adentro, de San Luis Potosí y Aguascalientes; también se incluyen las letras de periodistas y autores residentes en el norte y algunos del sureste del país; a estos se suman las propuestas originales de autores de diversos países hispanoamericanos, citados anteriormente.

\section{Novelas y reseñas seriadas}

La difusión de las novelas de folletín en la prensa del siglo XIX fue muy popular, además de rentable para los periódicos y los autores. Los capítulos se presentaban, por lo general, en la parte inferior de la primera página del diario; su redacción mantenía el suspenso para que el lector público continuara su lectura caracterizada, en voz alta, en cada edición. Se conoce que la lectura de estas novelas seriadas se leían en voz alta y su público las seguía semana a semana guiados por un lector (Ortiz Monasterio 2005: 57). 
La crítica literaria y los estudios posteriores sobre historia de la literatura latinoamericana suelen definir el folletín como un género literario específico identificado como "novela popular". Algunos estudios adoptan esta categoría acuñada por Jorge B. Rivera (1968), que supera la valoración negativa de las producciones por entrega, de la crítica precedente, y abre las puertas a los estudios académicos sobre literatura popular (Ortiz Monasterio 2005).

Entre las novelas en serie publicadas en El Correo Español, en este periodo de estudio, destacan:

- "Culpa y castigo" y "Luchas del destino", de Félix María Alcérreca, con nueve entregas.

- "La familia Rico", de Evaristo Rodríguez de Bedía, con 27 entregas.

- "La Puchera", de José María Pereda con 30 entregas.

- La novela corta "Mariquita" de Manuel Sancho en cuatro entregas.

Asimismo se introdujeron reseñas literarias y ensayos críticos sobre la literatura. Esta crítica empírica de poesía y prosa se publicó en la columna: "Autores y libros" de mayo de 1890 a octubre de 1892, que contenía breves reseñas de obras de la literatura, clásica y moderna, a manera de notas descriptivas sin firma, y en la "Crónica Semanal" firmada con pseudónimo Delineator, en donde se presentaron obras en prosa en siete entregas, del 13 mayo al 8 de julio de 1894.

Similares a las entregas literarias, resalta la publicación de dos series con un enfoque didáctico: "El Diccionario Yucateco", obra inédita de Feliz Ramos y Duarte en cuatro entregas, de julio a agosto de 1891. Y la "Reseña Histórica de la Lengua y Literatura Española" en diez entregas, publicada en diciembre de 1892.

Desde 1895 se presentaron ensayos críticos sobre la situación de España, antes de que iniciara el conflicto bélico de la guerra hispano-estadounidense, y que culminaría en 1898 con la pérdida de sus colonias en América y Asia.

En el último número publicado por el fundador del periódico, el 31 de mayo de 1898, solamente hay una colaboración literaria. Esta aparece entre cartas editoriales y notas informativas, firmado con el pseudónimo Duque de Cantabria, se trata de un poema punzante titulado "Sampson y yo" que lleva el subtítulo Diálogo púnico mano a mano; este incluye palabras en spanglish y se refiere al bombardeo que hizo la armada estadounidense en 1898 , sin previo aviso, sobre una zona ocupada por civiles. Como ese poema de crítico, se publicaron algunos otros de tono satírico; igualmente se incluyeron ensayos seriados que analizaron el conflicto de la guerra hispanonorteamericana (El Correo Español 1898). 


\section{Conclusión}

Durante el siglo XIX, el estímulo promovido por el periodismo para la divulgación de las letras, poesía y prosa, generó un interés público por la literatura. En Europa, el avance de la educación propició el aumento del mercado editorial y de lectores. En América Latina, la modernización en todos sus aspectos fue un fenómeno desigual (Ramos 2003: 12). El desarrollo editorial fue menor debido al rezago en la educación, pero la prensa fue el medio más popular para el fomento de la lectura de obras literarias.

Las valiosas colaboraciones literarias en las páginas de El Correo Español, en una o en varias entregas, algunas inéditas y muchas duplicadas en otros diarios españoles y mexicanos, y en los de otros países latinoamericanos, permiten ver con detalle la circulación de sus producciones. En estas se confirman sus habilidades como prosistas y poetas, además de las crónicas periodísticas, actividad que estuvo altamente relacionada con el quehacer literario del periodo junto a otras actividades profesionales que desarrollaban muchos de los autores, algunos eran notarios, funcionarios públicos y otros más empresarios culturales.

Del total de las colaboraciones literarias, ${ }^{30}$ en este diario españolista, los porcentajes de los textos publicados fueron los siguientes:

- $58 \%$ de los textos que se consignan son de autores españoles;

- $23 \%$ pertenece a escritores mexicanos;

- $13 \%$ de autores de varios países latinoamericanos y

- $6 \%$ son traducciones al español, de las cuales más de la mitad corresponden a literatos franceses (Elizalde 2017: 28).

Estos escritos literarios publicados en las páginas del periódico constituyen una fuente de investigación considerable, escasamente estudiados, pues permiten hacer acercamientos desde diversas especialiadades del aporte de las letras españolas, mexicanas y de otras nacionalidades al repertorio de la literatura que se construía y difundía en la prensa de finales del siglo XIX.

\footnotetext{
30 La publicación de obras literarias, suman 1.981. En este total no se incluyen notas críticas sobre la literatura.
} 


\section{Referencias bibliográficas}

BAZANT, M. (2009). Laura Méndez de Cuenca. Mujer indómita y moderna (1853-1928). Vida cotidiana y entorno. México: El Colegio Mexiquense/Gobierno del Estado de México. Recuperado de https://bit.ly/2IDii9P

CUESTA, E. (2016). El modernismo en la prensa mexicana, siglo XIX. Manuscrito.

DÍAZ ALEJO, A. E. (2002). Edición crítica, introducción, notas e índices. Obras IX, Manuel Gutiérrez Nájera. Periodismo y literatura. Artículos y ensayos (1877-1894), Coordinación de Humanidades, México: UNAM.

EL CORREO ESPAÑOL, Tomo I, Año 1, núm. 1, Elizalde, F.L. J., “Nuestros propósitos. Programa de "El Correo Español". México, 9 de noviembre de 1889.

EL CORREO ESPAÑOL, Tomo X, Año X, núm. 2,408, Elizalde, F.L. J. México, 31 de mayo de 1898.

ELIZALDE, L. (2016). El Correo Español. Aportes a la prensa periódica en México (18891898). México: UAEM-Bonilla Artigas Editores, MemoriaPublica no 5

ELIZALDE, L. (2017). Índices literarios. El Correo Español (1889-1898). Eliezer Cuesta Gómez y Patricia Romero Ramírez (Colaboradores). México; UAEM-Bonilla Artigas Editores, MemoriaPublica no 6.

HENRÍQUEZ UREÑA, M. (1962). Breve historia del Modernismo. México: Fondo de Cultura Económica.

LEDEZMA MARTÍNEZ, J. M. (2013). "Telesforo García: un emigrante montañés en el Porfiriato". XV Encuentro de Latinoamericanistas Españoles (pp. 990-1000). Cairo Carou, Heriberto, Almudena Cabezas González, Tomás Mallo Gutiérrez, Esther del Campo García y José Carpio Martin (Eds.). Madrid: Trama editorial/CEEIB. Recuperado de https://bit.ly/2T1nWrl

MEJíAS ALONSO, A. y ARIAS COELLO, A. (1998). La prensa del siglo XIX como medio de difusión de la literatura hispanoamericana. Revista general de información y documentación, vol. 8, no 2, pp. 241-257. Recuperado de https://eprints.ucm.es/21696/1/Prensa_Siglo_XIX.pdf

MORA, P. (2009) Presentación. En Mora, Pablo y Ángel Miquel (compiladores y editores). Españoles en el periodismo mexicano siglo XIX y XX. México: UNAM, Instituto de Investigaciones Bibliográficas, UAEM, Fundación Carolina, pp 15-20.

OSSORIO Y BERNARD, M. (1904). Ensayo de un catálogo de periodistas españoles del siglo XIX (1903-1904). Madrid: Imprenta y litografía de J. Palacios. Recuperado de https://archive.org/details/ensayodeuncatlo00berngoog 
ORTIZ MONASTERIO, J. (2005). "La revolución de la lectura durante el siglo XIX en México". Revista Historias no 60, pp. 57-75. Instituto Nacional de Antropología e Historia. Recuperado de https://bit.ly/2ThFEWJ

PÉREZ GAY, R. “Prensa porfirista. La vida por entregas". Nexos no 213. México, febrero, 1987. Artículo disponible en http://www.nexos.com.mx/?p=4729

RAJO SERVENTICH, A. (2017). “EI hispanoamericanismo visto por la prensa española. Los casos de La Época y El Imparcial”. Pacarina del Sur vol, año 8, núm. 30, Recuperado de https://bit.ly/2T2uRjH

RAMOS, J. (1989 reimp. 2003). Desencuentros de la modernidad en América Latina. Literatura y política en el siglo XIX, México: Fondo de Cultura Económica. Recuperado de https://bit.ly/2BUp1XI

ROSS, S.R. "El historiador y el periodismo mexicano", Historia Mexicana Vol. 14, No. 3 (Jan. - Mar., 1965), pp. 347-382. México: El Colegio de Mexico. https://www.jstor.org/stable/25135272?seq=1\#page_scan_tab_contents

SIMÓN PALMER, M. C. (1989). La ocultación de la propia personalidad en las escritoras del siglo XIX. Actas del IX Congreso de la Asociación Internacional de Hispanistas 18-23 agosto 1986. Volumen II, Berlín, Frankfurt am Main, Vervuert (pp. 91-97). Recuperado de https://bit.ly/2ThlxXG

VARGAS CRUZ, H. R. (2018). "Félix María Alcérreca. Teoría Musical BC". Recuperado de https://bit.ly/2NwBogT

VIEYRA SÁNCHEZ, L. (2007). "Segunda propuesta para escribir la historia de la prensa española en México". Reseña Boletín de Investigaciones bibliográficas. México, pp. 279-283. Recuperdo de https://bit.ly/2XkJ8Gt

VIVEROS ANAYA, L.A. (2006). Estudio introductorio y revisión crtica. Ciro B. Ceballos, Panorama mexicano 1890-1910 (Memorias). México: Coordinación de Humanidades/UNAM. 